\title{
Hotspots and Trends of Teenagers Cyberbullying Based on WoS
}

\author{
Wei He, Qi Su* \\ School of Education Science, Nanjing Normal University, Nanjing, China \\ Email: *lingbomanbu628@qq.com
}

How to cite this paper: He, W., \& Su, Q. (2020). Hotspots and Trends of Teenagers Cyberbullying Based on WoS. Open Journal of Social Sciences, 8, 100-110. https://doi.org/10.4236/jss.2020.811010

Received: October 10, 2020

Accepted: November 9, 2020

Published: November 12, 2020

Copyright (C) 2020 by author(s) and Scientific Research Publishing Inc. This work is licensed under the Creative Commons Attribution International License (CC BY 4.0).

http://creativecommons.org/licenses/by/4.0/

\begin{abstract}
With the popularization of the Internet, cyberbullying has become a complicated aspect of school bullying. Understanding the current hotspots of cyberbullying among teenagers is a benefit for relevant education managers. In this study, SPSS was used to conduct cluster analysis of relevant literatures collected in Web of Science (WoS) core journal before December 31, 2019. According to the results of the analysis, the hotspots in the research on teenagers' cyberbullying can be classified into four themes: 1) definitions and characteristics of cyberbullying, 2) mental health problems caused by cyberbullying, 3) strategies of cyberbullying, and 4) the relationship between gender difference and cyberbullying. Future research needs to coordinate the governance of teenagers' living and learning environment from three aspects: family, school and social media, such as paying attention to parents' family education mode, school education, monitoring and management mechanism of social network, etc., and promote the establishment of teenagers' personal good values and the reflection of bystander behavior from the perspective of others.
\end{abstract}

\section{Keywords}

Teenagers Cyberbullying, Cluster Analysis, Hotspots, Trends

\section{Introduction}

In recent years, the problem of school bullying has aroused public concern. With the widespread use of online social platforms, face-to-face bullying begins to move to digital platforms, thus forming cyberbullying. Smith et al. (2008) define cyberbullying as an aggressive, intentional act carried out by a group or individual, using electronic forms of contact, repeatedly and over time against a victim who cannot easily defend him or herself. Watts et al. (2017) suggest that cyber- 
bullying is defined as intent to repeatedly harass someone using any electronic method, including social media, and includes defamation, public disclosure of private facts, and intentional emotional distress. From the above definitions, the essential characteristics of cyberbullying include electronic media, intentional attacks, repetitive bullying for a long time, and the power imbalance between cyberbullies and victims. Therefore, cyberbullying also adds a new and more complex character to the traditional bullying problem (Huang \& Chou, 2010). According to a survey by the National Center for Education Statistics (NCES) of America (Indicators of School Crime and Safety, 2010; Indicators of School Crime and Safety, 2017), teenagers were the main victim of cyberbullying. With the increasing popularity of computers and mobile phones, the proportion of students being bullied in school dropped from 28\% to 21\% from 2005 to 2015, but the proportion of cyberbullying was increasing year by year. In 2007, $4 \%$ of middle and high school students suffered from cyberbullying. In 2013, about 7\% of middle and high school students reported being cyberbullied in the school. In $2015,11.5 \%$ of students in public middle and high schools were cyberbullied. Middle school students were at the highest risk of cyberbullying, but by high school the risk began to decline (Williams \& Guerra, 2007). Middle and high school students are going through adolescence, a critical period in human development. Harmful experiences during this period can cause serious and lasting consequences. At the same time, it also causes trouble to human relationship and interaction in the school. Therefore, cyberbullying in middle and high school is regarded as an urgent problem in social, health and education, which has aroused the concern of researchers, social workers and scholars. This study analyzed the literatures related to the research of teenagers' cyberbullying in the core collection of Web of Science (WoS), summarized the current research hotspots of cyberbullying in middle and high schools, and sorted out the definition, methods, problems and countermeasures of cyberbullying. Finally, this study discusses how to reduce the phenomenon of cyberbullying in practice from the aspects of environmental construction and interpersonal relationship improvement.

\section{Data Processing and Research Methods}

\subsection{Data Sources}

The data used in the study collected from the Web of Science core collection database. The database is an important database for obtaining global academic information. The target papers were searched in the core collection of Web of Science on Dec. 31, 2019. The search string "TS = ((high school OR middle school OR secondary school OR senior high school OR senior middle school OR junior high school OR junior middle school) and (cyberbullying OR teenager cyberbullying))" was used to obtain the target literatures. TS stands for topic, which means searching the literature in the form of topic. Here 654 records are shown on the screen (See Figure 1). Based on the focus of research on the development of 


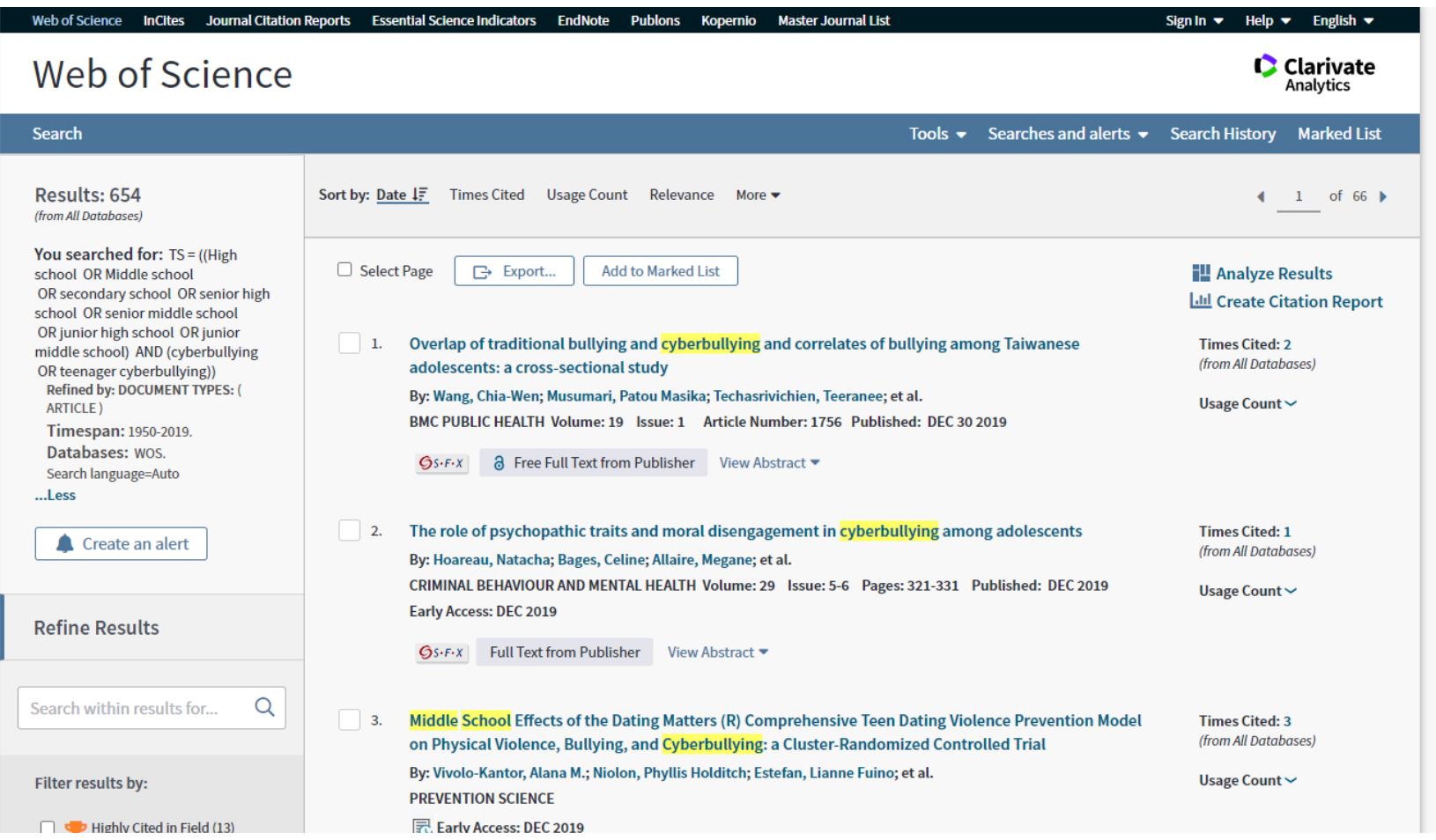

Figure 1. Original search results in WoS.

this field, the document type was limited to "Article", and the search period was unlimited. The language was English. Then, the irrelevant papers and less representative record types are excluded, such as news, biography, advertisements, notices and press releases. As a result, 535 relevant papers were found from WoS.

\subsection{Research Methods}

To ensure that the 535 articles retrieved were not exist duplicated and irrelevant, all the literatures were screened by reading the abstract and full text, and a total of 527 target literatures were finally obtained. Bicomb (Bibliographic Item Co-Occurrence Matrix Builder) was used to sort out the keywords of 527 papers, and constructed a text matrix and co-word matrix of high-frequency keywords. Then SPSS 20.0 was used for cluster analysis to reveal the hotspots and trends of the research on teenagers' cyberbullying in middle and high schools. Finally, the representative articles were selected for content analysis.

\section{Data Analysis and Results}

\subsection{Annual Number of Articles}

As shown in Figure 2, the research related to the middle and high school students' cyberbullying began to attract the attention of scholars in the early of $20^{\text {th }}$ century. The first relevant paper was published in 2006. From 2006 to 2011, the average annual number of papers published was no more than 10 . The research on teenagers' cyberbullying in middle and high schools developed slowly in this 


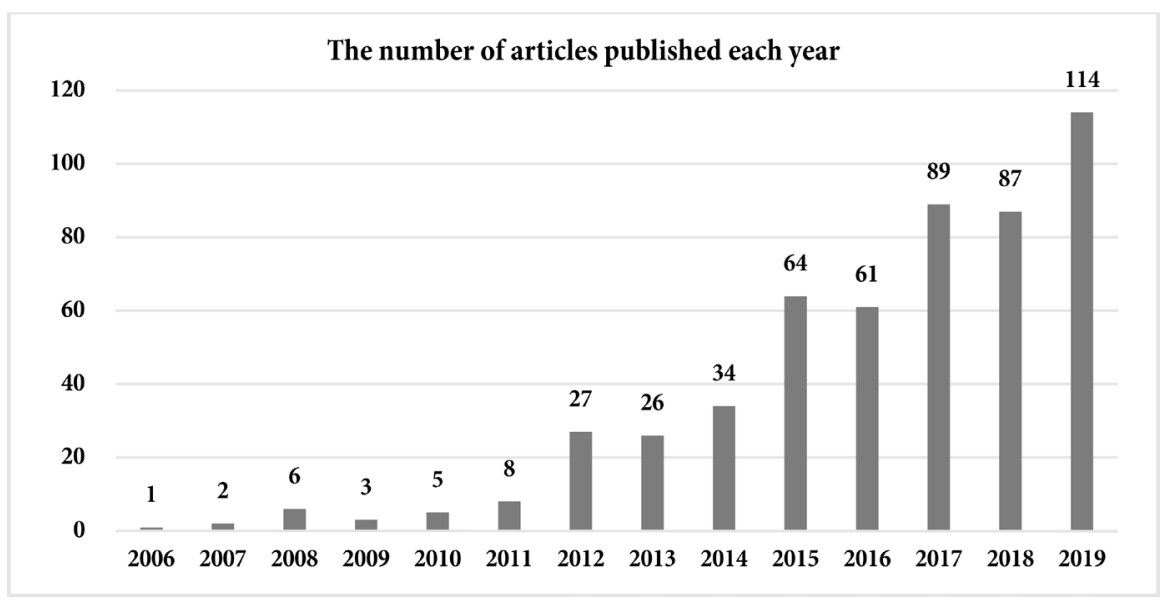

Figure 2. The annual number of articles.

period. The number of papers published in 2012 increased rapidly compared with that in 2011, indicating that the problem of teenagers' cyberbullying has gradually attracted attention since 2011, which is a developing period for the research of teenagers cyberbullying. The number of articles published in 2015 showed a significant increase compared with 2014, indicating that research on cyberbullying among middle and high school students has received widespread attention. There were abundant papers on cyberbullying among the middle and high school students published in 2019 than previous year.

\subsection{Keywords List}

Keywords represent the core content of an article. By analyzing and summarizing the key words in the literature of a certain field, the research hotspots in this field can be revealed to some extent. The first 26 keywords were selected as high-frequency keywords (see Table 1), which were with frequency $>11$, and the cumulative frequency was $48.4 \%$, which met the analysis criteria. As represented in Table 1, except for "cyberbullying", the top ten keywords: "bullying", "adolescents", "cyber victimization", "adolescence”, “victimization”, "bystander”, "victims", "perpetration", "gender", and "traditional bullying". This result indicated that the research on teenagers cyberbullying mostly focus on the forms and gender of bullying, while the deeper relationship between keywords needs further data mining.

\subsection{Cluster Analysis}

Cluster analysis plays a role of dimensionality reduction, and data with similar topics can be formed into a group. The data within the group are highly similar, while the differences between the groups are large. The aim of cluster analysis is to segregate groups with similar traits and assign them into clusters. After analysis, the clustering analysis chart of high frequency keywords of cyberbullying is obtained (see Figure 3). The keywords were classified into four topics: 1) definitions and characteristics of cyberbullying, which mainly involve cyberbullying, 
Table 1. High-frequency keywords.

\begin{tabular}{|c|c|c|}
\hline Ranking & Keywords & Frequency \\
\hline 1 & cyberbullying & 407 \\
\hline 2 & bullying & 161 \\
\hline 3 & adolescents & 131 \\
\hline 4 & cyber victimization & 59 \\
\hline 5 & adolescence & 56 \\
\hline 6 & victimization & 51 \\
\hline 7 & bystander & 27 \\
\hline 8 & victims & 25 \\
\hline 9 & perpetration & 23 \\
\hline 10 & gender & 22 \\
\hline 11 & traditional bullying & 21 \\
\hline 12 & school & 20 \\
\hline 13 & school bullying & 19 \\
\hline 14 & suicide & 17 \\
\hline 15 & mental health & 17 \\
\hline 16 & prevention & 16 \\
\hline 17 & self-esteem & 16 \\
\hline 18 & coping strategies & 15 \\
\hline 19 & aggression & 15 \\
\hline 20 & moral disengagement & 15 \\
\hline 21 & depression & 14 \\
\hline 22 & internet & 14 \\
\hline 23 & empathy & 14 \\
\hline 24 & intervention & 14 \\
\hline 25 & cyber harassment & 12 \\
\hline 26 & suicidal ideation & 12 \\
\hline 27 & parents & 12 \\
\hline 28 & gender differences & 12 \\
\hline
\end{tabular}

bullying, cyber victimization, and victimization, etc.; 2) mental health problems caused by cyberbullying mainly involve suicide, suicide ideation, and depression, etc.; 3) strategies of cyberbullying mainly include intervention, coping strategies, and prevention, etc.; 4) the relationship between gender difference and cyberbullying, which mainly include gender difference, gender, etc.

\section{Recommendations}

After the cluster analysis, it revealed that the research on teenagers cyberbullying 
Dendrogram using Average Linkage (Between Groups)

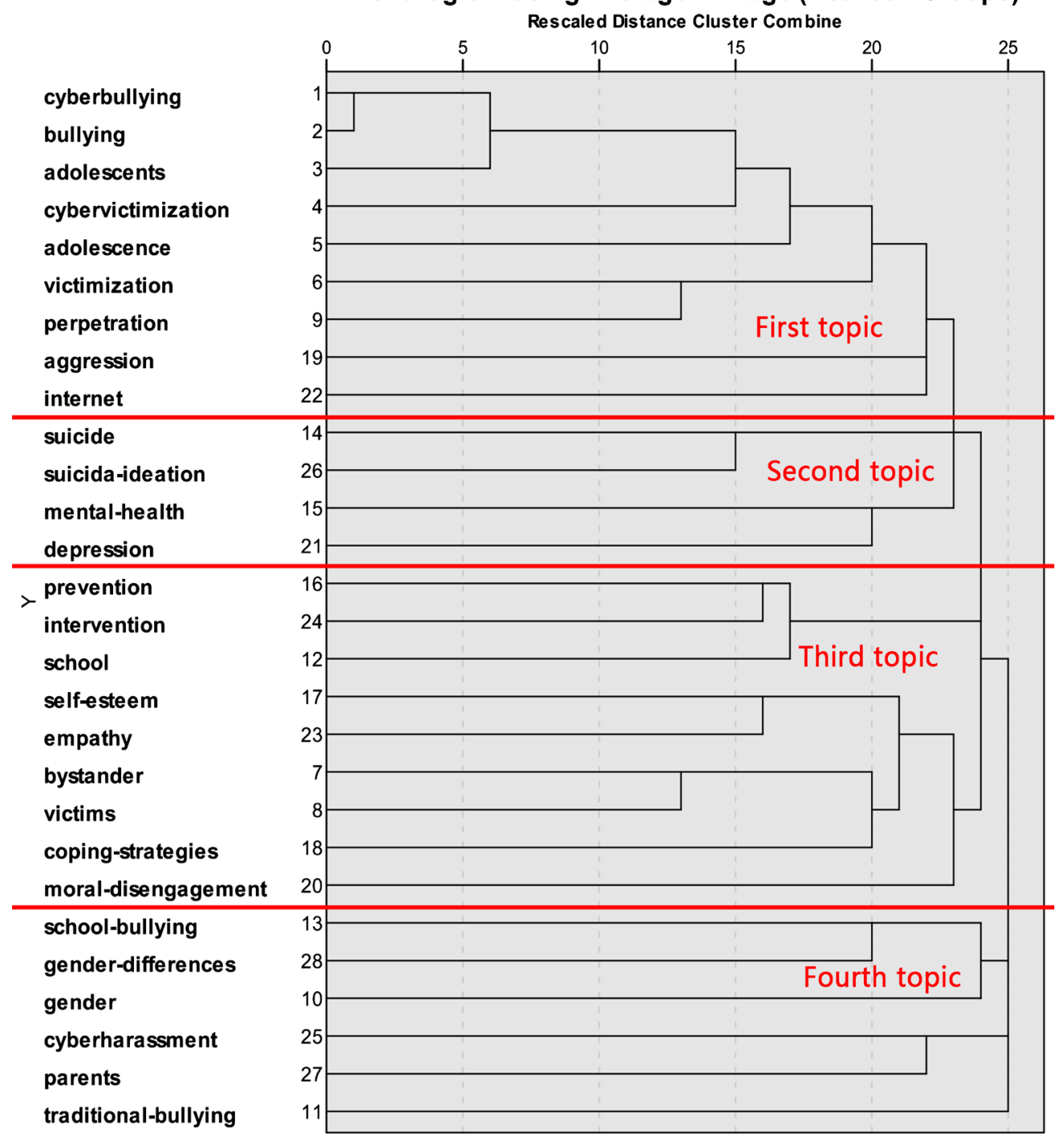

Figure 3. Cluster analysis diagram of high-frequency keywords.

mainly focused on four topics: 1) definitions and characteristics of cyberbullying, 2) mental health problems caused by cyberbullying, 3) the intervention strategies of cyberbullying, and 4) the relationship between gender difference and cyberbullying. Among them, the current research hotspots at home and abroad include: a) the definition and characteristics of cyberbullying among teenagers and $b$ ) the intervention strategies of cyberbullying. The intervention measures of cyberbullying are the key topics in the research of cyberbullying among teenagers. In general, the intervention of teenagers' cyberbullying can be shaped from the external environment and the individual level of teenagers to resist the occurrence of cyberbullying.

\subsection{External Environment: Collaborative Governance of Family, School and Society}

Home and school are the main places in the life of middle and high school stu- 
dents, and the social environment their contact with is exposed to the network environment. However, the middle and high school students who are in adolescence are susceptible to the temptation and influence of external factors. Therefore, to create a relatively healthy and harmonious external environment is conducive to students to establish a correct concept of network security.

Build trust between parents and children, and promote empathy in children. Previous studies have found that parents of cyberbulliers were often prone to use punitive or severe parenting methods to supervise children through physical punishment, filtering friends, and monitoring the Internet (Kalmus, Blinka, \& Lafsson, 2015). Such excessive control of parents will be hated by adolescents. A lack of trust and communication between parents and children can also contribute to these behaviors. However, active parental mediation and good family relationship made it easier to create a relaxed family environment and increased the likelihood that students would talk to their parents when they were hurt. In addition, enhancing the emotional communication between parents and children can promote the reflective and empathic behavior of adolescents, prevent aggressive and supportive aggressive attitudes, and thus reduce the online risk activities of middle and high school students (Gómez-Ortiz, Romera, Ortega-Ruiz, \& Del Rey, 2018; Álvarez-García, Núñez, Garcia, \& Barreiro-Collazo, 2018).

Schools are the most relevant environment for the social development of teenagers. From the perspective of school prevention, it is important to ensure that schools have sound anti-bullying norms and introduce anti-cyberbullying programs or content into the classroom to raise the anti-bullying awareness of students. For example, the task-oriented WebQuest course immediately and effectively enhanced the knowledge of cyberbullying, reduced the intentions, and retained the effects after the learning (Ming-Shinn, Wu, Leif, Koustuv, \& Scott, 2013). Some scholars believe that the prevention of cyberbullying should combine the traditional school bullying and cyberbullying, and design a video game (https://www.cybereduca.com/) (Landazabal \& Martínez-Valderrey, 2015; Maite \& Martínez-Valderrey, 2018). This game covering five topics: 1) network phenomenon, 2) computer technology and security, 3) cybersexual behavior, 4) the consequences of cyberbullying, and 5) dealing with cyberbullying. After a year of empirical research, the results showed that students' empathy, self-esteem and interpersonal conflict resolution ability were significantly improved, and the number of both types of aggressive behaviors was reduced. In addition, the gender difference in cyberbullying is related to age. Schools should develop personalized measures based on the characteristics of students, such as using the Pestkoppenstoppen online project, tailoring intervention measures for cyberbullying based on the personal characteristics of participants, teaching young people how to cope with cyberbullying more effectively (Jacobs, VoLlink, Dehue, \& Lechner, 2014).

Relying on media technology, cyberbullying information is widely disseminated, which can strengthen the transmission of monitoring information, curb 
the circulation of bullying content, effectively reduce the spread of bullying information and reduce harm. Many scholars use recognition technology and prediction models to identify bullying information, such as analyzing text features, image contents, social graph parameters, and temporal contents, but the accuracy is still limited, and the relevant psychological research results are largely ignored. Silva (Silva, Hall, \& Rich, 2018) adopted an interdisciplinary approach to develop an automated model for identifying and measuring the degree of cyberbullying in social network sites, and a Facebook app. The proposed model matches streams or bursts of messages with information from adolescents' social media profiles, which notifies parents about the likelihood that their adolescent is a cyberbullying victim. Therefore, social media plays an important role in the network media environment, which can help with families and schools to curb the spread and deepening of cyberbullying. For example, when media reports on issues such as traditional bullying or cyberbullying related to students, the relevant information should be more detailed based on evidence. Social learning theory of suicide contagion (Pirkis, Burgess, Francis, Blood, \& Jolley, 2006) believes that media reports may make suicide more culturally acceptable, stimulating imitation by observers who have similar experiences with the content of the report, which has greater increases in suicides.

\subsection{Personal Accomplishment: Shaping Good Psychological Quality and Responsibility}

Under the protection of a good external environment, when students face cyberbullying, their reactions have an important connection with their internal psychological qualities. These findings revealed that adolescents' level of cyberbullying increases as their hopelessness increases and decreases as their value increases (Bülent, 2017). For the victim of bullying, those who tend to attribute the cause of the accident to themselves are more likely to suffer than those who attribute it to others or accidents (Bauman, 2011). Therefore, teenagers should improve their internal psychological quality, learn to control anger, enhance prosocial behavior, and improve their skills in conflict resolution.

Establish our own awareness of responsibility, and increase the intervention of cyberbullying. Whether it is traditional school bullying or cyberbullying, nearly half of teenagers may be bystanders (Knauf, Eschenbeck, \& Hock, 2018). Therefore, mobilizing bystanders and raising their awareness of responsibility are promising goals in anti-cyberbullying projects. However, the role of bystanders in cyberspace is complicated. As for bystanders of cyberbullying, there will be different performances, such as helping the victim, reinforcing bullying behavior or keeping silent (Wright, 2016). For example, bystander's behavior that express approval by forwarding and thumbing up bullying messages will increase the bulliers' satisfaction with their own behavior, thus strengthening bullying. Bystanders who ignore bullying and keep silent may also be considered as acquiescence to bullying; Bystanders commenting from the perspective of the victim in online comments will inspire other bystanders to defend the victim. The ano- 
nymity of the Internet reduces bystanders' fear of the negative consequences caused by the intervention, but cyberspace technology has also changed the way observers view the incident. More than half of adolescents consider cyberbullying to be unrelated to themselves and choose to be silent (Desmet, Bastiaensens, Van Cleemput, Poels, Vandebosch, Cardon et al., 2016). In cyberspace, when bystanders witness cyberbullying, it is difficult for them assess the situation correctly because they can't catch the emotional response from the victim directly and sometimes do not even know the identity of the victim. In addition, they may blame the victim because they may have less contextual information about the victim in case of cyberbullying, which makes the attacks seem justified. At the same time, the invisibility of the bystander, the physical distance from the victim, the delayed attention to the bullying incident, and the potential presence of many other bystanders also promote the transfer of responsibility, weaken their sense of responsibility, and promote the passivity of intervention. Therefore, it is a major task of anti-cyberbullying to improve students' information interpretation ability and form correct network moral values.

\section{Conclusion and Limitations}

In sum, the current study helps investigators know the trend of bullying among teenager research. The recommendations in this study are helpful for researchers to intervene cyberbullying so as to reduce the occurrence of cyberbullying. The study highlights the fact that cyberbullying among adolescents needs to be given sufficient attention because it can have a negative impact on their social and emotional development. The current study found that the research on teenagers' cyberbullying mainly discussed four topics. That is 1) definitions and characteristics of cyberbullying, 2) mental health problems caused by cyberbullying, 3) the intervention strategies of cyberbullying, and 4) the relationship between gender difference and cyberbullying. To prevent cyberbullying, individuals, parents, schools and society need to work together. Future research on online bullying among teenagers will focus on how to prevent it. In line with this, this study put forward several suggestions from students' external environment and students' own factors to reduce cyberbullying.

There are some limitations of the current study need to be noted. First, the data in this study were limited to English articles in core journals of WOS, which may to some extent affect the analysis results. More comprehensive literature can be obtained from more databases in the future to dig new findings. Second, since the conclusion of this study was obtained by analyzing the high-frequency keywords of target literatures, it is not allowed to infer the causal relationship between each of them. But these data do provide some needed description of the research on cyberbullying among adolescents, revealing the possible effects of cyberbullying on adolescents and offering some suggestions. Larger cross-sectional and longitudinal studies may need in future studies to extend these findings. Thirdly, this study only included literature written in English; more comprehen- 
sive results can also be obtained if multiple languages are considered and compared in the future studies.

\section{Funding}

This research was supported by the Priority Academic Program Development of Jiangsu Higher Education Institutions in China.

\section{Author's Contributions}

Qi Su has designed the research. Wei He analyzed the data, and prepared the first draft of the paper. Qi Su as the corresponding author contributed to the revision. All authors approved the final draft.

\section{Conflicts of Interest}

The authors declare no conflicts of interest regarding the publication of this paper.

\section{References}

(2010). Indicators of School Crime and Safety. https://www.bjs.gov/content/pub/pdf/iscs10.pdf

(2017). Indicators of School Crime and Safety. https://www.bjs.gov/content/pub/pdf/iscs17.pdf

Álvarez-García, D., Núñez, J. C., Garcia, T., \& Barreiro, A. (2018). Individual, Family, and Community Predictors of Cyber-Aggression among Adolescents. European Journal of Psychology Applied to Legal Context, 10, 79-88. https://doi.org/10.5093/ejpalc2018a8

Bauman, S. (2011). Bullying and Cyberbullying among Deaf Students and Their Hearing Peers: An Exploratory Study. Journal of Deaf Studies and Deaf Education, 16, 236-253. https://doi.org/10.1093/deafed/enq043

Bülent, D. (2017). The Relationship between Adolescents' Levels of Hopelessness and Cyberbullying: The Role of Values. Educational Sciences Theory \& Practice, 17, 1119-1133.

Desmet, A., Bastiaensens, S., Van Cleemput, K., Poels, K., Vandebosch, H., Cardon, G. et al. (2016). Deciding Whether to Look after Them, to Like It, or Leave It: A Multidimensional Analysis of Predictors of Positive and Negative Bystander Behavior in Cyberbullying among Adolescents. Computers in Human Behavior, 57, 398-415. https://doi.org/10.1016/j.chb.2015.12.051

Gómez-Ortiz, O., Romera, E., Ortega-Ruiz, R., \& Del Rey, R. (2018). Parenting Practices as Risk or Preventive Factors for Adolescent Involvement in Cyberbullying: Contribution of Children and Parent Gender. International Journal of Environmental Research \& Public Health, 15, 2664. https://doi.org/10.3390/ijerph15122664

Huang, Y. Y., \& Chou, C. (2010). An Analysis of Multiple Factors of Cyberbullying among Junior High School Students in Taiwan. Computers in Human Behavior, 26, 1581-1590. https://doi.org/10.1016/j.chb.2010.06.005

Jacobs, N. C., VoLlink, T., Dehue, F., \& Lechner, L. (2014). Online Pestkoppenstoppen: Systematic and Theory-Based Development of a Web-Based Tailored Intervention for Adolescent Cyberbully Victims to Combat and Prevent Cyberbullying. BMC Public Health, 14, 396. https://doi.org/10.1186/1471-2458-14-396

Kalmus, V., Blinka, L., \& Lafsson, K. (2015). Does It Matter What Mama Says: Evaluating 
the Role of Parental Mediation in European Adolescents' Excessive Internet Use. Children \& Society, 29, 122-133. https://doi.org/10.1111/chso.12020

Knauf, R. K., Eschenbeck, H., \& Hock, M. (2018). Bystanders of Bullying: Social-Cognitive and Affective Reactions to School Bullying and Cyberbullying. Cyberpsychology, 12, Article 3. https://doi.org/10.5817/CP2018-4-3

Landazabal, M. G., \& Martínez-Valderrey, V. (2015). Effects of Cyberprogram 2.0 on "Face-to-Face" Bullying, Cyberbullying, and Empathy. Psicothema, 27, 45-51.

Maite, G., \& Martínez-Valderrey, V. (2018). Technological Resources to Prevent Cyberbullying during Adolescence: The Cyberprogram 2.0 Program and the Cooperative Cybereduca 2.0 Videogame. Frontiers in Psychology, 9, 745. https://doi.org/10.3389/fpsyg.2018.00745

Ming-Shinn, L., Wu, Z. P., Leif, S., Koustuv, D., \& Scott, J. G. (2013). Cyber Bullying Prevention: Intervention in Taiwan. PLoS ONE, 8, e64031. https://doi.org/10.1371/journal.pone.0064031

Pirkis, J. E., Burgess, P. M., Francis, C., Blood, R. W., \& Jolley, D. J. (2006). The Relationship between Media Reporting of Suicide and Actual Suicide in Australia. Social Science \& Medicine, 62, 2874-2886. https://doi.org/10.1016/j.socscimed.2005.11.033

Silva, Y. N., Hall, D. L., \& Rich, C. (2018). Bullyblocker: Toward an Interdisciplinary Approach to Identify Cyberbullying. Social Network Analysis \& Mining, 8, 18. https://doi.org/10.1007/s13278-018-0496-z

Smith, P. K., Mahdavi, J., Carvalho, M., Fisher, S., \& Tippett, N. (2008). Cyberbullying: Its Nature and Impact in Secondary School Pupils. Journal of Child Psychology and Psychiatry, 49, 376-385. https://doi.org/10.1111/j.1469-7610.2007.01846.x

Watts, L. K., Wagner, J., Velasquez, B., \& Behrens, P. I. (2017). Cyberbullying in Higher Education: A Literature Review. Computers in Human Behavior, 69, 268-274. https://doi.org/10.1016/j.chb.2016.12.038

Williams, K. R., \& Guerra, N. G. (2007). Prevalence and Predictors of Internet Bullying. Journal of Adolescent Health, 41, 14-21. https://doi.org/10.1016/j.jadohealth.2007.08.018

Wright, M. F. (2016). A Social-Ecological Approach to Cyberbullying (pp. 121-149). New York: Nova Science Publishers. 